\title{
КОЛЛЕКТОРЫ, ПОКРЫШКИ, ПЕРЕХОДНЫЕ ЗОНЫ (ПРИНЦИПЫ И МЕТОДЫ ОБРАБОТКИ КАПИЛЛЯРИМЕТРИИ В РАМКАХ МОDЕRN)
}

Еникеев Б.Н., Сиирнов О.A.

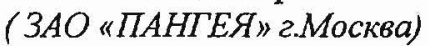

Известный анекдот о том, что не всем стоит покупать в подарок книжную новинку, если одна книга у поздравляемого давно уже есть, можно с элементом обреченности вспомнить, анализируя отношение к обработке данных капилляриметрии.

К сожалению, в России средний уровенъ разнообразия, теоретической нагружкенности и обоснованности петрофизических взаимосвязей в последнее десятилетие только падает. Отразилось это и на обработке данных капилляриметрических кривых, не взирая на серьезные работы в этом направлении проводимые такими исследователями как В.И.Петерсилье и Л.М.Дорогиницкая.

Одним из отечественных инструментов дпя обработки и иктерпретации кривых капилляриметрии является инструментарий используемый в пакете ModERn. B соответствии с базовой идеологией ModERn как программного средства для открытия (пополнения или подтверждения) знаний, деятельность по интерпретации капилляриметрии носит не менее плюралистичный характер и сочетает часть или все нижеперечисленные действия:ввод данных из EXCEL

рассмотрение "зоологии кривых" (наличие нескольких мод и их выпуклость-вогнутость);

отбраковку или изменение веса разных участков кривых

ручной подбор параметров подбираемых теоретических кривых к эмпирическим данным; оптимизационную идентификацию параметров теоретических кривых; интерактивное уточнение подобранных параметров в случае их неудовлетворительности; расчет кривых фазовых проницаемостей по теоретическим аптроксимациям с использованием идентифицированных параметров среды;

расчет по идентифицированным параметрам, вязкости и заданной доле обводненности значений

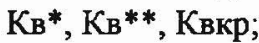

дифференциация семейств капиллярньт кривых и кривых фазовой проницаемости по выбранному параметру (стратиграфия, глубина, гидравлический радиус, петротип, диапазон продуктивности пласта и т.п.);

расчет параметров переходной зоны при заданных значениях плотности и поверхностного натяжения флюидов;

интерактивная кластеризация выделенных объектов по параметрам капиллярных кривых; распознавание номеров выделенных кластеров по показаниям керна, каротажа, сейсмическим атрибутам и оценка его надежности;

сохранение результатов (как в ModErn, так и в EXCEL) в виде, притодном для последующего анализа при обработке данных для других месторождений.

Суцественным элементом описанной технологин работ, все фрагменты которой в той или иной

мере используются в практике обработки данных капилляриметрии, являются несколько особенностей, перечисленных ниже:

- регрезентативная и расширяемая библиотека теоретических кривых капилляриметрии (в настоящий момент, кроме Burdine, используются более широко применяемые на Западе методы расчета Genuchten-Mualem и Chirecini) и возможность оценить точность получаемых прогнозов за счет ошибки неадекватности моделн;

- наборы констант, показывающих значения параметров поверхностного натяжения и вязкости для различных типов флюидов при различной температуре и давленни;

- профессиональные программные средства идентификации параметров, заложенные в ModERn.

- интегрированность в пакет ModERn, допускающий статистический анализ и кластеризацию и многомерную визуализацию данных.

Опыт работ по подготовке петрофизического обоснования подсчетных работ и кластеризацик разреза на петротипы показывает, что наиболее узким местом для повсеместного использования кривых капилляриметрии при дифференциация на петротипы является относительно малый объем их определений, что особенно характерно для месторождений с небольшими запасами. Дополнктельную информацию об алгоритмах и взаимосвязях можно найти на форуме по петрофизике www.petrophysics.borda.ru

\section{ЛИТЕРАТУРА}

1. Chierici, G. L., 1981. Novel relations for drainage and imbibition relative permeabilities. SPE Paper 10165.

2. AMBRUS, J., Hurtado, F. S. V, Maliska, C. R., Silva, A. F.C., CONTESSI, B. A., Cordazzo, J., and 2004. Uma Metodologia de Estimação de Parâmetros Aplicada à Determinação de Curvas de Permeabilidade Relativa, CILAMCE - XXV Iberian Latin-American Congress on Computational Methods in Engineering, Recife, Pernambuco, Brazil. 